A subgroup of stakeholders participated in a group modelbuilding workshop to develop causal maps on the determinants of physical inactivity, unhealthy diet and effective healthcare delivery in the Caribbean. Data from the qualitative and quantitative reviews were applied to further develop the causal structures.

Results Stakeholders reinforced the need for upstream interventions including the provision of a healthy food environment and sustainable urban development facilitating active living, supported by fiscal incentives (subsidies) and disincentives (taxes). Stakeholders emphasised car-based development as a major driver of physical inactivity including a lack of infrastructure for active transport, a high social regard for car usage and a lack of social support for physical activity. Unhealthy diet, according to stakeholders, was driven by changing social structures in the home, the marketing and distribution of highly processed foods, and limited access to locally produced fresh fruits and vegetables. The causal maps are serving as the basis for a stakeholder-driven policy simulation model that will be validated against quantitative evidence. Conclusion The interconnectedness of diabetes determinants highlights the importance of a multi-sectoral response and a systemic approach to decreasing the diabetes burden. The simulation model aims to aid Caribbean policymakers in evaluating the potential impact of different policy options on future diabetes prevalence and mortality. The overall utility of this approach to stakeholder engagement and option appraisal will be assessed and developed further for use in other resourceconstrained settings.

\section{OP74 UNDERSTANDING THE PROCESS OF DEVELOPING AND IMPLEMENTING CHRONIC DISEASE POLICIES IN THE CARIBBEAN REGION: A QUALITATIVE POLICY ANALYSIS}

${ }^{1,2} \mathrm{C}$ Guell ${ }^{*},{ }^{3} \mathrm{MM}$ Murphy, ${ }^{3,4} \mathrm{TA}$ Samuels, ${ }^{3} \mathrm{~L}$ Bishop, ${ }^{2,4} \mathrm{~N}$ Unwin. ${ }^{1}$ European Centre for Environment and Human Health, University of Exeter, Truro, UK; ${ }^{2} \mathrm{MRC}$ Epidemiology Unit and Centre for Diet and Activity Research (CEDAR), University of Cambridge, Cambridge, UK; ${ }^{3}$ Faculty of Medical Sciences, University of the West Indies, Cave Hill Campus, Barbados; ${ }^{4}$ Chronic Disease Research Centre, University of the West Indies, Bridgetown, Barbados

\subsection{6/jech-2017-SSMAbstracts.73}

Background The Caribbean, like other middle income regions, experiences a significant burden of non-communicable diseases (NCDs), and responded in 2007 with a heads of government declaration committing to a range of policy measures. In 2015, this multi-method qualitative evaluation study investigated the progress made in seven Caribbean countries; this paper reports the findings of an analysis of the process that helped or hindered the development and implementation of policies.

Methods We conducted analysis of relevant policy documents, and 76 semi-structured interviews with 80 stakeholders from government (ministries of health, education); civil society (academia, agricultural, health and church organisations) and private businesses. Interviews were conducted by two regional teams. The initial pragmatic coding and categorisation of data with the software Dedoose was deductively framed by the WHO NDC Action Plan, and guided by a Multiple Streams policy approach and realist principles. This was complemented by further inductive thematic analysis and synthesis by the authors.
Results Two overarching themes emerged related to the process that guided the development, adaptation and implementation of regional policy goals into local settings.First, stakeholders reported a commonly shared recognition of the need for multi-sectoral partnerships but were frustrated by the difficulties of achieving this in practice. Country-specific NCD commissions served as case studies for both positive experiences of achieving 'whole of society' collaboration and difficulties in equitable representation and translation into government-led action. In settings with more effective multisectoral working it was possible to identify 'policy entrepreneurs' who had the profile and traction to promote cross sectoral action. Second, stakeholders highlighted the importance and opportunity provided by policy transfer. When comparing policy creation across small islands, most success has been made in areas such as tobacco control that could use an international framework and roadmap as a template. As policy efforts were most advanced in larger, more resource-rich countries, some stakeholders called for more synergetic working on policy solutions across countries. They felt that policy transfer could be improved in a region of relatively small countries but benefitting from a strong regional agenda, cooperation and professional exchange.

Conclusion Stakeholders' local and regional insight, expertise and experience helped to explain the processes that supported or hindered effective policy-making in different settings or different policy areas. Triangulating their reflections with a document review helped to corroborate and strengthen their assessment, provide contextual information to reports and also identified gaps in documentation and narratives.

\section{OP75 CATALYSING GLOBESITY: AN ANALYSIS OF THE IMPACT OF US FREE TRADE AGREEMENTS ON CALORIC INTAKE FROM A NATURAL EXPERIMENT IN CANADA USING THE SYNTHETIC CONTROL METHOD}

${ }^{1} \mathrm{P}$ Barlow*, ${ }^{2} \mathrm{M}$ McKee, ${ }^{1} \mathrm{D}$ Stuckler. ${ }^{1}$ Department of Sociology, University of Oxford, Oxford, UK; ${ }^{2}$ Department of Health Services Research and Policy, London School of Hygiene and Tropical Medicine, London, UK

\subsection{6/jech-2017-SSMAbstracts.74}

Background Free trade and investment agreements (FTAs) are often implicated in the global pandemics of overweight, obesity, and related diseases. Concerns centre on how FTAs increase population exposure to unhealthy, high calorie diets rich in salt, sugar, and fat. Yet the empirical evidence to support these concerns is limited, both methodologically and substantively. Thus, few existing studies of FTAs and dietary change have accounted for unobserved confounding, and many were unable to differentiate the impact of FTAs from contemporaneous macroeconomic and policy changes. Moreover, few have examined any potential effect of FTAs on total caloric intake, despite its critical role in the aetiology of obesity. Here we address these limitations by analysing a unique natural experiment from the unanticipated implementation of the Canada-US Free Trade Agreement (CUSFTA) in 1989.

Methods We use data from the UN Food and Agricultural Organisation and the synthetic control method to test the hypothesis that CUSFTA increased caloric intake in Canada. We also anlayse whether these changes were accompanied by increased US investment and imports in the Canadian food and beverage sector. Finally, we simulate the population impact on weight gain of these changes in caloric intake using 